\title{
Interleukin-1 Is an Astroglial Growth Factor in the Developing Brain
}

\author{
Dana Giulian,' Douglas G. Young, Janet Woodward, Dale C. Brown, ${ }^{1}$ and Lawrence B. Lachman ${ }^{1}$ \\ Department of Neurology and Program of Neuroscience, Baylor College of Medicine, Houston, Texas 77030, and \\ 'Department of Cell Biology, The University of Texas at Houston, M. D. Anderson Hospital and Tumor Institute, Houston, \\ Texas 77030
}

\begin{abstract}
The immunomodulator interleukin-1 (IL-1) is found to be an astroglial growth factor during development of the mammalian brain. In vitro studies indicate that ameboid microglia, a class of brain mononuclear phagocytes, are the likely source of IL-1. Examination of different brain regions during development shows IL-1 production only after the appearance of ameboid microglia. These observations suggest that brain mononuclear phagocytes secrete growth factors that regulate normal growth and development of the CNS.
\end{abstract}

Astroglia play an important role in determining the structural organization of the brain through diverse actions upon neurons (Rakic, 1972; Aguayo et al., 1981; Silver et al., 1982). During embryogenesis, primitive astroglia found in radial patterns provide routes along which neurons migrate from germinal zones to cortical regions of the CNS (Bignami and Dahl, 1974; Schmechel and Rakic, 1979; Levitt and Rakic, 1980). At later periods in brain development, astroglia secrete extracellular matrix constituents, including laminin, which are thought to promote selective axonal growth (Letourneau, 1975; Lander et al., 1982; Hopkins et al., 1985). In adult brain, clusters of "reactive" astroglia collect at sites of injury and appear to block the regrowth of axons and regeneration of damaged neural tissue (Bignami and Dahl, 1974; Latov et al., 1979; Pares and Levine, 1982; Miller et al., 1986). The mechanisms that direct these various glial responses are doubtlessly complex. Recently, much attention has been given to growth factors isolated from developing or injured CNS (Lim, 1980; Pruss et al., 1981; Lemke and Brockes, 1984; Giulian and Baker, 1985; Giulian et al., 1985; Giulian and Young, 1986) as possible regulators of astroglial function. We report here that developing mammalian brain contains the immunomodulator interleukin-1 (IL-1), a secreted protein that serves as an astroglial growth factor. Our observations suggest that immunomodulators released by brain mononuclear phagocytes help to regulate growth of the CNS during embryogenesis.

\section{Materials and Methods}

Cell cultures. Albino rats (Holtzman, Madison, WI), timed for pregnancy, provided embryos and neonates used in these studies. After removal of the meninges, isolated cerebral cortices or cerebella were dissected in sterile PBS and dispersed by trituration in chemically defined medium (Bottenstein and Sato, 1979) containing DNase (1 mg/

\footnotetext{
Received May 19, 1987; revised July 22, 1987; accepted July 31, 1987.

This work was supported by Grants NS23113 and NS2063801 from NINCDS, EY04915 from NEI, a Teacher Investigator Award from NINCDS (D.G.), and funds from the March of Dimes.

Correspondence should be addressed to Dana Giulian, Department of Neurology, Baylor College of Medicine, One Baylor Plaza, Houston, TX 77030.

Copyright (C) 1988 Society for Neuroscience $0270-6474 / 88 / 020709-06 \$ 02.00 / 0$
}

$\mathrm{ml}$; Sigma Chemical Co., St. Louis, MO) and trypsin $(0.2 \% \mathrm{wt} / \mathrm{vol}$; Sigma). Mixed populations of glia were grown on poly-L-lysine-coated $22 \mathrm{~mm}$ glass coverslips in $35 \mathrm{~mm}$ dishes $\left(10^{6}\right.$ cells/dish) containing 1.5 ml chemically defined medium with $10 \%$ bovine calf serum. Cultures were placed in $1.5 \mathrm{ml}$ of chemically defined medium when tested for secretion of IL-1.

Interleukin-1 isolation and bioassays. The IL-1 assay was based on the incorporation of ${ }^{3} \mathrm{H}$-thymidine by murine thymocytes, as described elsewhere (Lachman et al., 1985). Briefly, thymuses from 8-12-weekold CD-1 mice (Charles River Breeding Farms, Wilmington, MA) were homogenized with a glass-Teflon hand homogenizer and thymocytes were cultured in Minimal Essential Medium containing 5\% human serum at a cell density of $1 \times 10^{7}$ cells $/ \mathrm{ml}$ in 96-well test plates. Serial dilutions of IL-1 were added to the thymocyte cultures and incubated for $48 \mathrm{hr}$ at $37^{\circ} \mathrm{C}$ in a humidified atmosphere of $5 \% \mathrm{CO}_{2} \cdot 6-{ }^{3} \mathrm{H}$-thymidine $(0.2 \mu \mathrm{Ci}, 2 \mathrm{mCi} / \mathrm{mmol}$; New England Nuclear) was added to each culture well for an additional $24 \mathrm{hr}$. After a total of $72 \mathrm{hr}$, the cultures were harvested onto glass fiber strips for scintillation counting.

To quantitate the number of units of IL-1, serial dilutions of samples were used to determine a response equal to $50 \%$ of a positive control. Units of IL-1 activity for brain fractions were calculated by the method of Schmitt and Ballet (1983).

As described earlier (Giulian et al., 1986a), we identified the brainderived $18 \mathrm{kDa}$ growth factor as IL-1 by coelution with rat macrophage IL-1 using gel filtration (Protein Pak 125; Waters) and anion-exchange chromatography (TSK-DEAE-5PW; Bio-Rad Laboratories). The partially purified brain-derived IL-1 was active in the D10 cell-line assay (Kaye et al., 1984) and could be neutralized by rabbit anti-murine IL-1 serum (assay performed by Dr. Mitchell Dukovitch in the laboratory of Dr. Steven Mizel).

Recombinant murine IL-1 (in the form of a precursor with $M_{\mathrm{r}} 31$ kDa) was kindly provided by Dr. Peter Lomedico (Hoffmann-LaRoche, Nutley, NJ), and recombinant human IL- $1 \alpha$ (rhIL- $1 \alpha$; Gubler et al., 1986) was purchased from Genzyme (Boston, MA). All recombinant samples showed less than $0.05 \mathrm{ng} / \mathrm{ml}$ of endotoxin, as detected by the limulus amebocyte lysate assay (Associates of Cape Cod).

Glial cell identifications and bioassays. Ameboid microglia containing acetylated low-density lipoprotein (ac-LDL) receptors were identified using ac-LDL bound to the fluorescent probe $1,1^{\prime}$-dioctaldecyl-1,3,3,3', $3^{\prime}$ tetramethylcarbindolocyanate (Dil) (Pitas et al., 1981). Ameboid micruglia were selectively destroyed by treatment for $6-12$ hr in chemically defined medium containing $5 \mathrm{~mm}$ L-leucine methyl ester (Sigma; 12, 16).

Indirect immunofluorescence techniques were used to identify astroglia containing glial fibrillary acidic protein (GFAP; Eng and DeArmond, 1982) or oligodendroglia containing galactocerebroside (Raff et al., 1979), as described earlier (Giulian et al., 1985). Proliferation of GFAP $(+)$ astroglia was monitored in mixed glial cultures isolated from embryonic rat cerebral cortex after $72 \mathrm{hr}$ incubation with IL-1. Mean counts of cells were obtained by determining cell numbers in 10 randomly selected fields $\left(0.314 \mathrm{~mm}^{2}\right)$ for each culture, as viewed by epifluorescence microscopy at $220 \times$. Prior to incubation with IL-1, about $10 \%$ of all cells were GFAP $(+)$ astroglia in E- 14 cultures and about $30 \%$ were GFAP $(+)$ cells in E-20 cultures.

Light-microscopic autoradiography was performed on cultures of dissociated E-20 brain that had been grown in medium containing $10 \mu \mathrm{Ci} /$ $\mathrm{ml}$ of $6-{ }^{-3} \mathrm{H}$-thymidine (sp act, $22 \mathrm{Ci} / \mathrm{mmol}$; Amersham) for $15 \mathrm{hr}$ prior to fixation. Coverslips mounted to glass slides were dipped in Kodak NTB2 emulsion diluted 1:1 with $\mathrm{dH}_{2} \mathrm{O}$ and developed with Kodak 

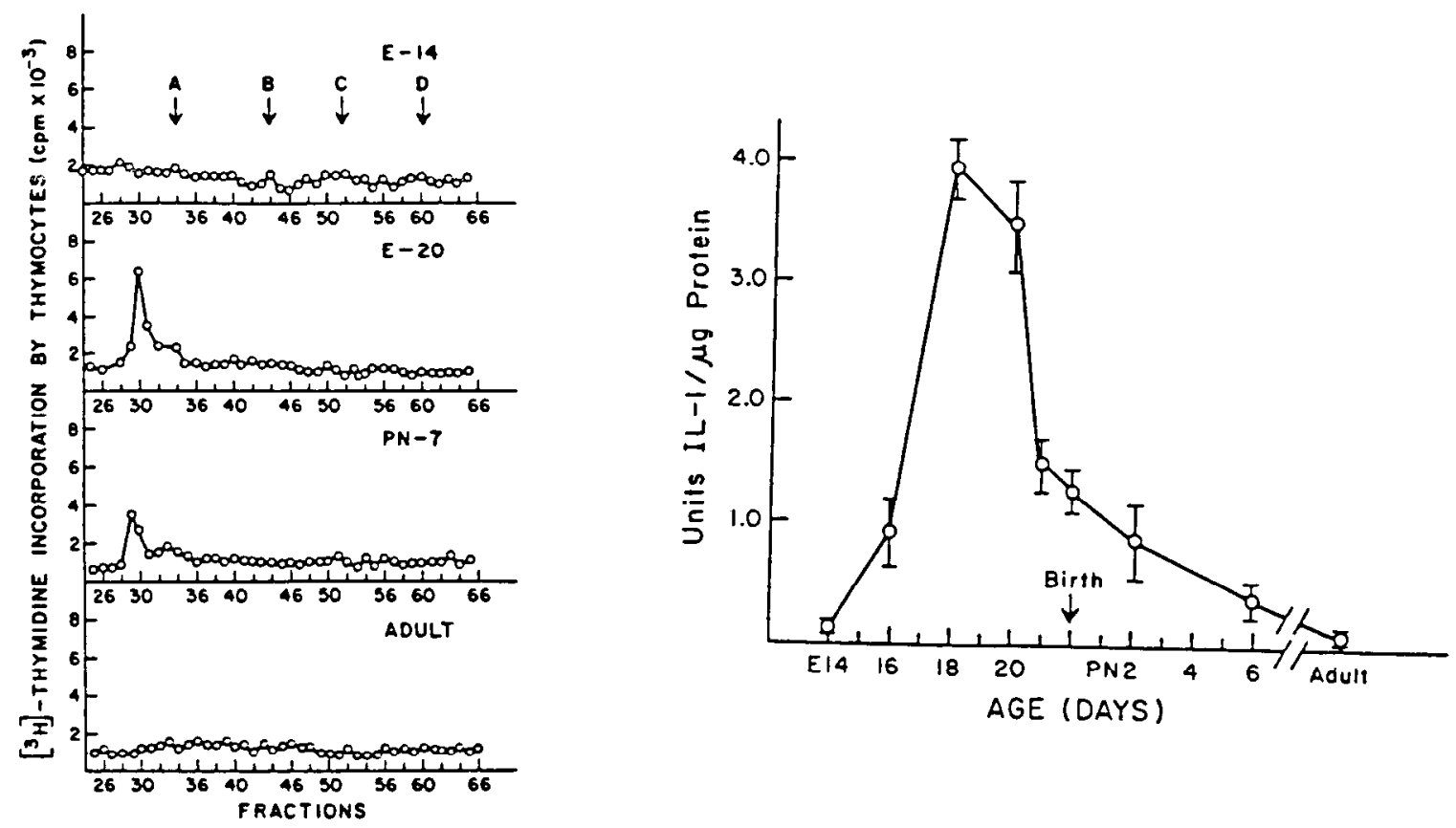

Figure 1. The appearance of IL-1 during development of the cerebral cortex. Left, Pooled sonicates of cerebral cortices from embryos (E-14 and E-20), postnatal (PN-7), or adult rats were prepared for column chromatography by sonication in PBS, followed by $0.45 \mu \mathrm{m}$ membrane filtration and centrifugation of $15,000 \times \mathrm{g}$ for $30 \mathrm{~min}$. Gel filtration was performed on a $100 \times 0.9 \mathrm{~cm}$ column (P-10; BioRad) on samples containing 5$10 \mathrm{mg}$ of protein. Fractions of $700 \mu \mathrm{l}$ were collected and assayed for IL-1 activity in the murine thymocyte ${ }^{3} \mathrm{H}$-thymidine-incorporation assay. IL-1 activity, detected in the $18 \mathrm{kDa}$ region, was recovered from the brain homogenates of late fetal period animals (embryonic E-20) and early postnatal period animals (PN-7). Gel-filtration fractions of sonicates from animals of the early embryonic stage (E-14) and adult brain did not contain IL-1 activity. Myoglobulin peptides were used to calibrate the column (in kDa): $A, 17 ; B, 8.5 ; C, 6.2 ; D, 2.5$. Right, IL-1 activity, expressed as units $/ \mu \mathrm{g}$ brain protein, was measured in supernatants of rat cerebral cortex that were fractioned by gel filtration, as for the left panel. All samples were frozen and assayed simultaneously in the murine thymocyte assay. Peak activity was found around stage E-18, or that period when ameboid microglia were numerous and actively phagocytic.

Dektol Developer after a 4 week exposure. GFAP $(+)$ astroglia viewed at $1200 \times$ that showed greater than 10 grains/nucleus were scored as incorporating significant amounts of ${ }^{3} \mathrm{H}$-thymidine. The percentage of such labeled cells was determined by viewing 50 randomly selected GFAP $(+)$ cells/coverslip. More than $70 \%$ of GFAP $(+)$ cells in cultures treated with 10 units recombinant human IL- $\alpha$ (rhIL- $1 \alpha$ ) for $72 \mathrm{hr}$ were labeled, whereas less than $20 \%$ of cells were labeled in control cultures. Coverslips used for autoradiography, shown in Figure 4, were exposed for 5 months.

\section{Results}

Detection of interleukin-1 in developing brain

Astroglia containing GFAP proliferate in the cerebral cortex and ccrcbcllum of perinatal rat (Rakic, 1972; Lim, 1980; Giulian and Baker, 1985; Miller et al., 1986). We sought to characterize astroglial growth factors found in such developing tissues (Giulian and Baker, 1985; Giulian et al., 1985). Initial studies of brain extracts suggested the presence of the immunomodulator IL-1, an $18 \mathrm{kDa}$ peptide growth factor that serves as an activator of $\mathrm{T}$ cells and as a promotor of the inflammatory response (Dinarello, 1984). Cerebral cortices obtained from rats of different ages were dispersed by sonication in PBS, centrifuged for $30 \mathrm{~min}$ at $15,000 \times \mathrm{g}$, and the supernatant passed through a $0.45 \mu \mathrm{m}$ filter. A total of $5-10 \mathrm{mg}$ of soluble protein were eluted with PBS from a standardized gel-filtration column (Giulian et al., 1986b). Aliquots were tested for IL-1 activity using the murine thymocyte proliferation assay. As shown in Figure 1, a thymocyte-stimulating activity of about $18 \mathrm{kDa}$ was detected in brain supernatants at embryonic stage E- 20 and at postnatal day 7. Identification of this $18 \mathrm{kDa}$ activity as IL-1 was estab- lished, as described earlier, by coelution with rat macrophage IL-1 using anion-exchange chromatography, by neutralization with specific murine IL-1 antiserum, and by measurement of bioactivity in the D10 cell-line assay (Giulian et al., 1986a).

In order to quantitate the amount of brain IL-1 produced during development, soluble brain protein obtained from animals of different ages was fractionated by gel filtration. The 18 $\mathrm{kDa}$ fractions from each age group were pooled and concentrated by ultrafiltration (YM-2; Amicon). Using dose-response curves from the thymocyte assay, we determined the units of IL-1 activity $/ \mu \mathrm{g}$ brain protein (Lachman et al., 1985). The highest concentrations of IL- 1 in the normally developing cerebral cortex of rat appeared during the perinatal period from embryonic stages E-18 to the time of birth (Fig. 1, right panel). Normal adult brain had no measurable IL-1 activity, suggesting a decline in production of the immunomodulator with age.

\section{Appearance of ameboid microglia during embryogenesis}

Although a number of different cell types are reported to release IL-1, mononuclear phagocytes are among the most potent secretory cells (Dinarello, 1984). Recently, ameboid microglia phagocytic cells found in the CNS have been identified as one source of brain IL-1 (Giulian and Baker, 1986; Giulian et al., 1986a). Since ameboid microglia are quite active as phagocytes during development (Ling, 1981; Innocenti et al., 1983a), they are also likely producers of IL-1 in embryonic brain. Using a fluorescent probe for ac-LDL receptors-1,1'-dioctadecyl-1$3,3,3^{\prime}, 3^{\prime}$-tetramethylindocarbocyanine bound to ac-LDL (Dilac-LDL) - we determined the numbers of ameboid microglia in 

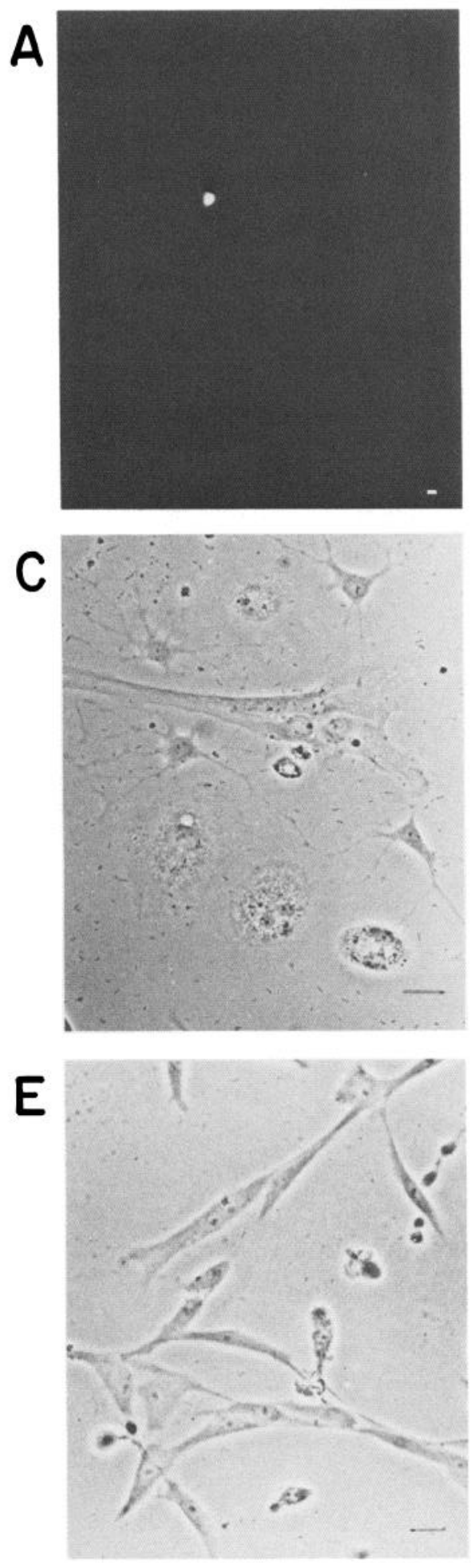
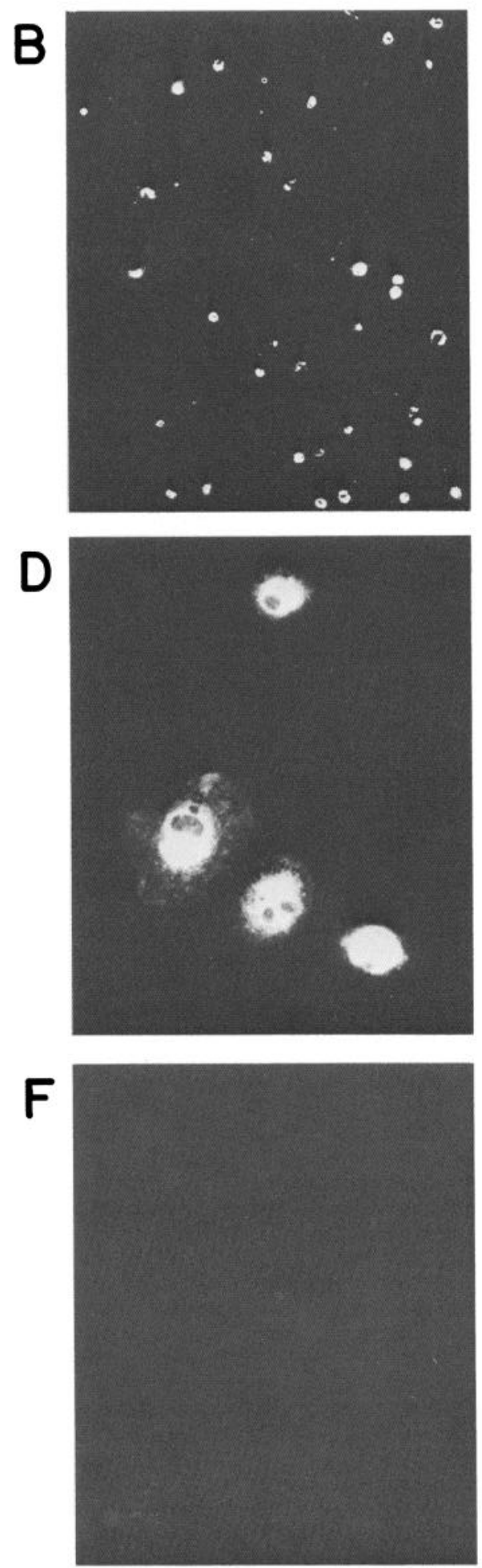

Figure 2. Microglia found in mixed brain cell cultures obtained from developing cerebral cortex of rat. Ameboid microglia containing the acetylated low-density lipoprotein receptor were identified by the fluorescent probe Dilac-LDL. Although few microglia were found in cultures obtained from the early embryonic period E-14 $(A)$, many were present by the late embryonic period E-20 $(B)$. Cultures obtained from postnatal day 1 rats $(C$, phase-contrast; $D$, fluorescence) also contained Dil-acLDL(+) microglia. Incubation of cultures with $5 \mathrm{~mm}$ L-leucine methyl ester for $12 \mathrm{hr}$ selectively destroyed the microglia $(E$ and $F$ ) (see also Table 1). Bar, $20 \mu \mathrm{m}$. freshly dissociated cerebral cortex taken from animals of different ages in the perinatal period. Although few Dil-ac-LDL(+) cells are present at stages E-14-15 (Fig. 2A), large numbers of Dil-ac-LDL(+) ameboid cells appear by stage E-20 (Fig. $2 B$ ). Quantitation of Dil-ac-LDL(+) cells (Table 1) indicates that the largest ameboid microglial population is found in the cerebral cortex near the time of birth (E-18 to PN-1), with a substantial drop in number by the second postnatal week.

\section{Ameboid microglia secrete interleukin-1}

In order to induce IL-1 secretion in vitro, embryonic glial cell cultures were stimulated by incubation with a macrophage activator, fixed Staphylococcus aureus (Dinarello, 1984; Giulian et al., 1986a). A stimulation index (IL-1 activity in a medium of cultures incubated with $S$. aureus/IL-1 activity in a medium of control cultures) was used to compare IL-1 release from glia 

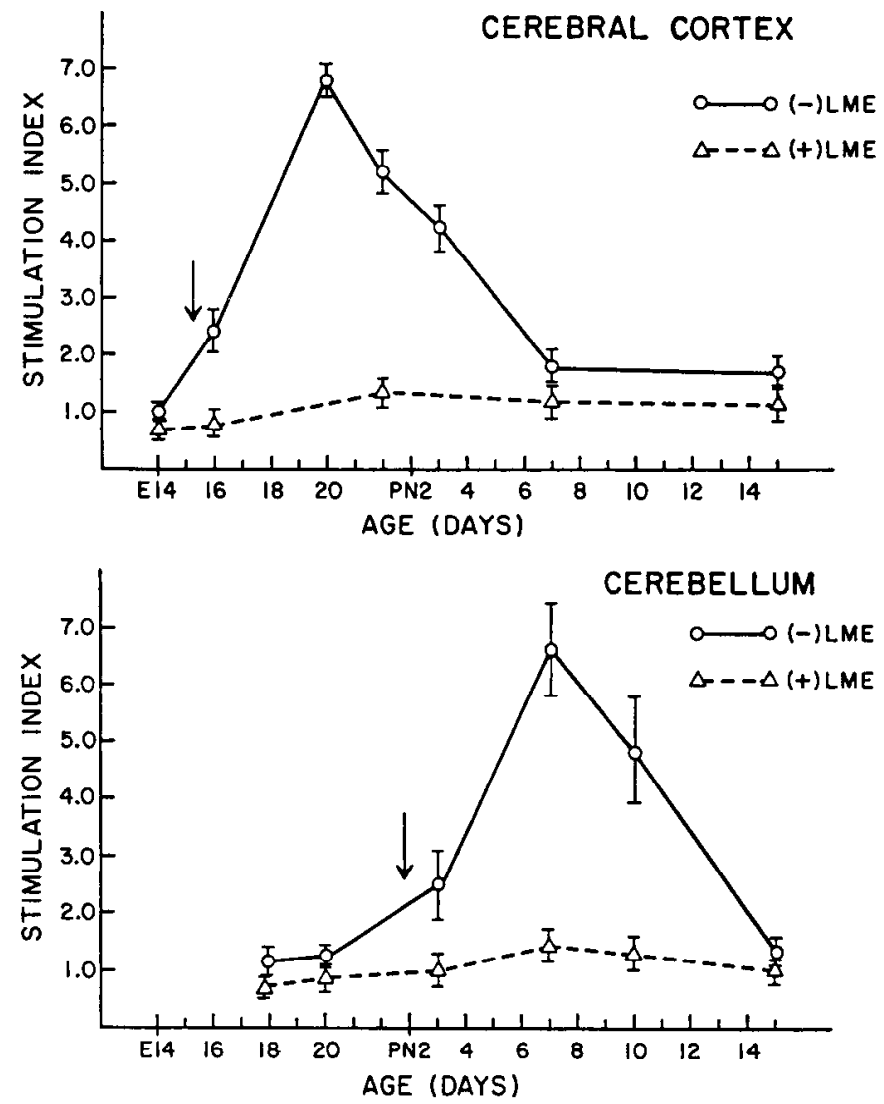

Figure 3. Stimulation index showing IL-1 release from cells of the developing brain. Glial cultures obtained from cerebral cortices of rats of different ages were incubated for $24 \mathrm{hr}$ with fixed $S$. aureus in order to elicit IL-1 secretion. The IL-1 activity in the conditioned medium was quantitated by ${ }^{3} \mathrm{H}$-thymidine incorporation using mouse thymocytes. The stimulation index for IL-1 release is given as a ratio of IL-1 activities for $S$. aureus-treated cultures/untreated control cultures. To confirm that ameboid microglia was the secretory cell, cultures were preincubated with L-leucine methyl ester (LME) in order to destroy Dilac-LDL $(+)$ cells. Top, Cerebral cortex. Bottom, Cerebellum. Arrows indicate the age at which ameboid microglia are first detected in these tissues.

obtained at different stages in development. We found that the peak of stimulated IL-1 secretion (E-18 to PN-1; Fig. 3) in vitro correlated both with IL-1 levels found in brain supernatants and with the appearance of Dil-ac-LDL(+) ameboid microglia in the cerebral cortex (Table 1). To confirm that embryonic microglia were in fact secreting IL-1, we selectively destroyed ameboid cells found in the mixed glial cell cultures using the lysosomotropic agent L-leucine methyl ester (Fig. 2D) (Thiele et al., 1983). As described earlier, L-leucine methyl ester will lyse Dilac-LDL(+) microglia (Fig. $2 E$ ), while sparing astroglia or oligodendroglia (Giulian and Baker, 1986). Under the conditions used, there was nearly a $95 \%$ destruction of ameboid microglia (Table 1). Embryonic brain cultures treated with $\mathrm{L}$-leucine methyl ester lacked microglia and produced very low levels of IL-1 (Fig. 3). Because these microglia-free cultures contained nearly $60 \%$ GFAP $(+)$ astroglia, we believe that astroglia are an unlikely source of IL-1 in the developing CNS (Fontana et al., 1982).

In rats, the cerebellum matures more slowly than the cerebral cortex (Valentino and Jones, 1981; Murabe and Sano, 1982; Matsumoto and Ikuta, 1985). We found that cultures obtained from the cerebellum of the E-18 rat had significant numbers of GFAP $(+)$ astroglia but lacked Dil-ac-LDL $(+)$ microglia. By 3
Table 1. Ameboid microglia in cortex and cerebellum

\begin{tabular}{lcl} 
Age & $\begin{array}{l}\text { Number of ameboid } \\
\text { microglia/coverslip }\end{array}$ & $\begin{array}{l}\text { Number of } \\
\text { ameboid microglia } \\
\text { after LME }\end{array}$ \\
\hline Ameboid microglia in developing cerebral cortex & \\
E-14 & $300 \pm 100$ & N.D. \\
E-16 & $1500 \pm 400$ & $300 \pm 200$ \\
E-18 & $6600 \pm 500$ & $100 \pm 100$ \\
PN-1 & $5500 \pm 600$ & $100 \pm 100$ \\
PN-15 & $2800 \pm 1100$ & $200 \pm 200$ \\
Ameboid microglia in developing cerebellum & \\
E-18 & $200 \pm 100$ & N.D. \\
E-20 & $300 \pm 200$ & $100 \pm 100$ \\
PN-1 & $1200 \pm 600$ & $100 \pm 100$ \\
PN-7 & $7700 \pm 1400$ & $200 \pm 200$ \\
PN-10 & $7500 \pm 1000$ & $200 \pm 100$ \\
PN-15 & $2100 \pm 150$ & $300 \pm 200$
\end{tabular}

Freshly isolated dissociated cells from rats of the indicated ages were placed in $35 \mathrm{~mm}$ dishes containing a glass coverslip and incubated for $6 \mathrm{hr}$ with Dil-ac$\operatorname{LDL}(5 \mu \mathrm{g} / \mathrm{ml})$ in order to identify ameboid microglia. Cell numbers were estimated by determining Dil-ac-LDL $(+)$ cells found in 10 randomly selected fields $(0.314$ $\mathrm{mm}^{2}$ ) and corrected for the area of the $22 \mathrm{~mm}$ coverslip. Identical cultures were treated for $12 \mathrm{hr}$ with $5 \mathrm{~mm}$ L-leucine methyl ester (LME) in order to destroy ameboid microglia selectively (see Fig. 2). N.D., not detected.

d after birth, however, ameboid microglia did appear in the cerebellum, with the greatest number of Dil-ac-LDL $(+)$ cells appearing by the end of the first postnatal week (Table 1). The differences in the timing of appearance for ameboid cells in the cerebral and cerebellar tissues allowed us to examine further the role of microglia in the production of brain IL-1. As described above, we used $S$. aureus to elicit the release of IL-1 from cultured brain cells. In the case of cerebellar cultures, the peak of stimulated IL-1 release was around PN-7 (Fig. 3, bottom), which contrasts with the earlier peak of IL-1 release in the cerebral cortex at E-18-20 (Fig. 3, top). The elimination of ameboid cells by prior treatment of cerebellar cultures with L-leucine methyl ester substantially reduced the production of IL-1.

\section{Interleukin-1 as a mitogen for embryogenic astroglia}

Although the developing brain contained both IL-1 and IL-1secreting cells, it remained to be demonstrated that embryonic GFAP $(+)$ astroglia responded to IL-1. Mixed populations of cerebral cortical cells cultured from embryonic rats of different

Table 2. Embryonic astroglia growth in the presence of murine recombinant IL-1

\begin{tabular}{ll} 
Age & $\begin{array}{l}\text { Fold increase in GFAP- } \\
\text { positive astroglia }\end{array}$ \\
\hline E-14 & $1.5 \pm 0.4$ \\
E-16 & $3.3 \pm 0.2$ \\
E-20 & $7.0 \pm 0.6$
\end{tabular}

Mixed glia cell cultures ( $10^{6}$ cells $/ 35 \mathrm{~mm}$ dish) from cerebral cortex of embryonic rats were grown in $1.5 \mathrm{ml}$ defined medium for $72 \mathrm{hr}$ in the presence of 5 units of recombinant murine IL- 1 in $10 \mu \mathrm{l}$ PBS. The mean number of GFAP $(+)$ astroglia/ $\mathrm{mm}^{2}$ was determined by scoring 10 randomly selected fields $\left(0.314 \mathrm{~mm}^{2}\right)$ per culture. A minimum of 6 cultures were used per experimental group. Data are expressed as the mean fold increase \pm SE in GFAP $(+)$ cells in treated versus control cultures. Control cultures were incubated for the same period in $1.5 \mathrm{ml}$ defined medium, with the addition of $10 \mu$ l PBS. 

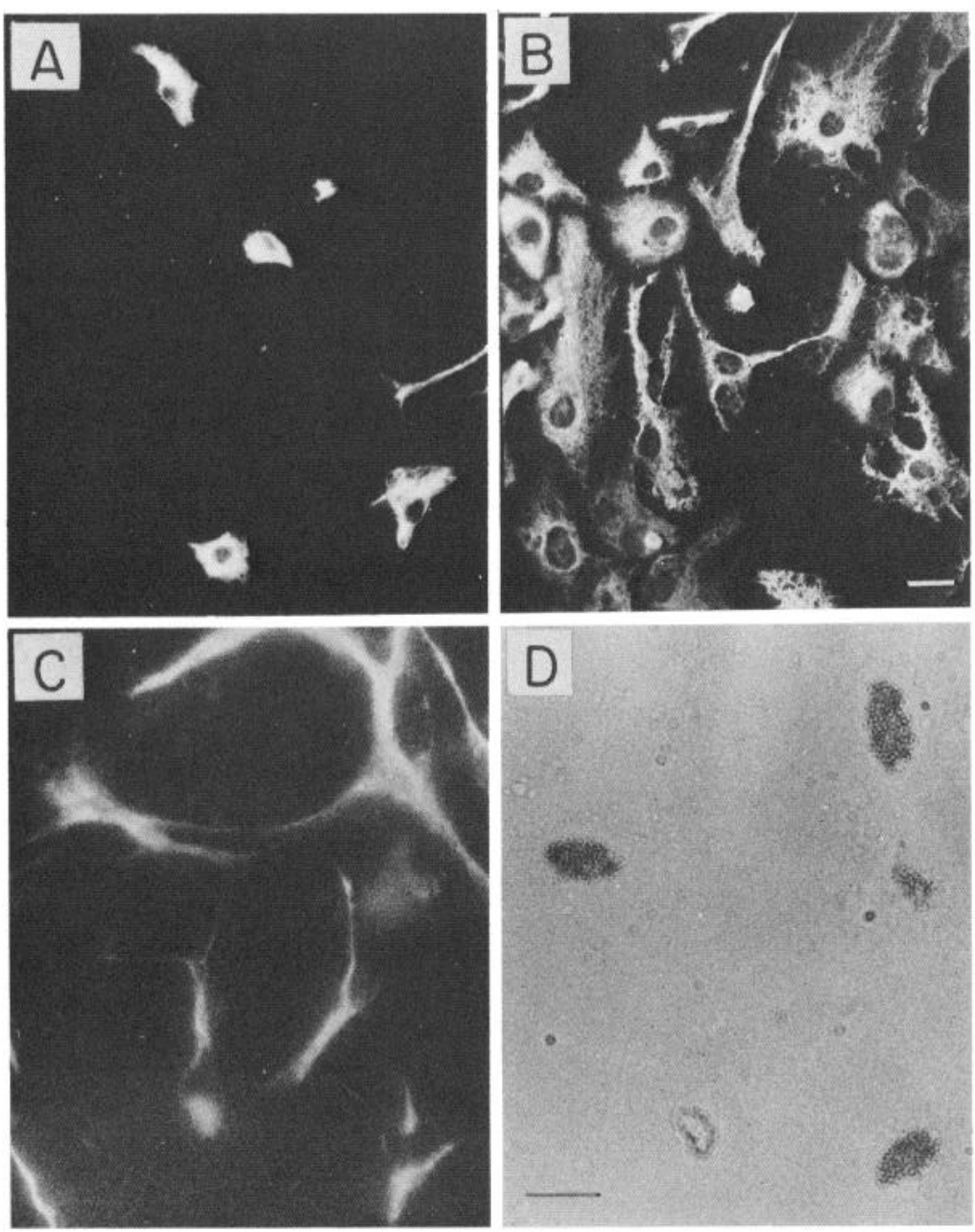

Figure 4. Stimulation of $\operatorname{GFAP}(+)$ astroglia in fetal cultures of dissociated cerebral cortex. Ten units of recombinant human IL- $1 \alpha$ were incubated with E-20 cortical cell cultures for $72 \mathrm{hr}$. As shown here, there was a 5-8-fold increase in GFAP $(+)$ cells in IL-1-treated cultures $(B)$, as compared to unstimulated control cultures $(A)$. About $70 \%$ of the IL-1-treated GFAP(+) astroglia, viewed by fluorescence microscopy $(C)$, show incorporation of ${ }^{3} \mathrm{H}$-thymidine $(D$, bright-field microscopy). Bar, $20 \mu \mathrm{m}$. ages were incubated for $72 \mathrm{hr}$ with recombinant murine IL-1. After incubation with recombinant murine IL-1, we observed increased numbers of GFAP $(+)$ astroglia in all embryonic stages tested with E-20 cells, showing a 7-fold elevation in the cell number (Table 2). rhIL- $1 \alpha$ also stimulated the proliferation of GFAP(+) astroglia 5-8-fold in E-20 cultures (Fig. 4). Cultures treated with rhIL- $1 \alpha$ showed that about $70 \%$ of E- 20 GFAP(+) astroglia had incorporated high concentrations of ${ }^{3} \mathrm{H}$-thymidine (Fig. 4), while less than $20 \%$ of cells in control cultures were labeled. In agreement with earlier reports (Giulian and Lachman, 1985; Giulian et al., 1986a), neither type of recombinant IL-1 altered the number of cultured galactocerebroside $(+)$ oligodendroglia or Dil-ac-LDL(+) microglia (data not shown). We did not assess the effects of IL-1 upon GFAP( $(-)$ or $\mathrm{GC}(-)$ precursor cells.

\section{Discussion}

By employing in vitro techniques and selective destruction of cells, we identify ameboid microglia as a principal source of IL-1 in the CNS during the perinatal period. Based on these observations, coupled with the fact that IL-1 serves as a mitogen for $\operatorname{GFAP}(+)$ astroglia, we propose that ameboid microglia, upon stimulation, help to regulate astroglial growth within specific sites of the normally developing brain. The mechanisms that activate microglia remain uncertain. Perhaps debris associated with cell death and extraneous axonal projections (In- nocenti et al., 1983a, b; Killackey, 1984) act as phagocytic signals that induce microglia to release astroglial growth factors. IL-1-stimulated astroglia may, in turn, help to direct pathways of axonal outgrowth or to stabilize newly formed circuits. In this way, we believe microglia play an important role in the maturation of the CNS.

During development, ameboid microglia seem to disappear from areas they once heavily populated (Rio Hortega, 1932; Ling et al., 1982). Such a decline in the ameboid cell population may result from death, emigration, or differentiation of microglia. Current work favors the third possibility, for several investigators note ameboid cells undergoing morphologic changes with the formation of long, thin branches (Rio Hortega, 1932; Ling et al., 1982; Perry et al., 1985). As ameboid cells differentiate into ramified microglia, they lose nonspecific esterase activity (Ling et al., 1982) and phagocytic function (Rio Hortega, 1932). We have observed similar changes in culture as ameboid microglia transform into ramified microglia with loss of ac-LDL receptors, nonspecific esterase, and phagocytic activity (Giulian and Baker, 1986). Such transformations from "macrophagelike" microglia into "quiescent" ramified microglia may account for the apparent loss of ameboid cells in maturing brain and the associated decline in IL-1 production.

Our hypothesis that microglia regulate astroglial growth is also supported by the recent discovery that recombinant IL-1 stimulates astrogliosis in vivo (Giulian, 1987). Further study 
with mRNA probes in situ may help to elucidate the sites of brain IL-1 production and action. This is the first report to suggest a role for IL- 1 in a developmental process and the first to link the immune system with growth of the immature brain. Our observations pose the possibility that IL-1-secreting cells help to mediate structural development in other organs.

\section{References}

Aguayo, A. H., S. David, and G. M. Bray (1981) Influences of the glial environment on the elongation of axons after injury: Transplantation studies in adult rodents. J. Exp. Biol. 95: 231-240.

Bignami, A., and D. Dahl (1974) Astrocyte-specific protein and radial glia in the cerebral cortex of newborn rat. Nature 252: 55-56.

Bottenstein, J. D., and G. H. Sato (1979) Growth of rat neuroblastoma cell line in serum-free supplemental medium. Proc. Natl. Acad. Sci. USA 76: 514-517.

Dinarello, C. A. (1984) Interleukin-1. Rev. Infect. Dis. 6: 51-56.

Eng, L. F., and S. H. DeArmond (1982) Immunocytochemical studies of astrocytes in normal development and disease. Adv. Cell Neurobiol. 3: 145-171.

Fontana, A., F. Kristensen, R. Dubs, D. Gemsa, and E. Weber (1982) Production of prostaglandin $\mathrm{E}$ and an interleukin-1 like factor by cultured astrocytes and $C_{6}$ glioma cells. J. Immunol. 129: 2413-2419.

Giulian, D. (1987) Ameboid microglia as effectors of inflammation in the central nervous system. J. Neurosci. Res. 18: 155-171.

Giulian, D., and T. J. Baker (1985) Peptides released by ameboid microglia regulate astroglial proliferation. J. Cell Biol. 101: 24112415

Giulian, D., and T. J. Baker (1986) Characterization of ameboid microglia isolated from the developing mammalian brain. J. Neurosci. 6: 2163-2178.

Giulian, D., and L. B. Lachman (1985) Interleukin-1 stimulates astroglial proliferation after brain injury. Science 228: 497-499.

Giulian, D., and D. Young (1986) Brain peptides and glial growth. 2. Identification of cells that secrete glial promoting factors. J. Cell Biol. 102: 812-817.

Giulian, D., Y. Tomozawa, H. Hindman, and R. Allen (1985) Peptides from the regenerating central nervous system promote specific populations of macroglia. Proc. Natl. Acad. Sci. USA 82: 4287-4290.

Giulian, D., T. J. Baker, L.-C. N. Shih, and L. B. Lachman (1986a) Interleukin- 1 of the central nervous system is produced by ameboid microglia. J. Exp. Med. 164: 594-604

Giulian, D., R. L. Allen, T. J. Baker, and Y. Tomozawa (1986b) Brain peptides and glial growth. 1. Glia-promoting factors as regulators of gliogenesis in the developing and injured central nervous system. J. Cell Biol. 102: 803-811.

Gubler, U., A. O. Chua, A. S. Stern, C. P. Hellmann, M. P. Vitek, T. M. Dechjara, W. R. Benjamin, K. J. Corrier, K. Kaffka, P. L. Kilian, D. Stromlo, B. H. Wittreich, D. Woehle, S. B. Mizel, and P. T. Lomedico (1986) Recombinant human Interleukin-1 $\alpha$ : Purification and biological characterization. J. Immunol. 136: 2492-2498.

Hopkins, J. M., T. S. Ford-Holevinski, J. P. McCoy, and B. W. Agranof (1985) Laminin and optic nerve regeneration in the goldfish. J. Neurosci. 5: 3030-3038.

Innocenti, G. M., S. Clarke, and H. Koppel (1983a) Transitory macrophages in the white matter of the developing visual cortex. I. Light and electron microscopic characteristics and distribution. Dev. Brain Res. 11: 39-54.

Innocenti, G. M., S. Clarke, and H. Koppel (1983b) Transitory macrophages in the white matter of the developing visual cortex. II. Development and relations with axonal pathways. Dev. Brain Res. 11: 55-66.

Kaye, J., S. Gillis, S. B. Mizel, E. M. Shevack, T. R. Malek, C. A. Dinarello, L. B. Lachman, and C. A. Janeway, Jr. (1984) Growth of a cloned helper $\mathrm{T}$ cell line induced by a monoclonal antibody specific for the antigen receptor: Interleukin-1 is required for the expression of receptors for Interleukin-2. J. Immunol. 133: 13391345.

Killackey, H. P. (1984) Glia and the elimination of transient cortical projections. Trends Neurosci. 7: 225-226.
Lachman, L. B., L.-C. N. Shih, and D. C. Brown (1985) Human interleukin-1 from leukemic monocytes. Methods Enzymol. (Immunochem. Techn.) 116: 467-472.

Lander, A. D., K. Fujii, D. Gospodarowicz, and L. F. Reichardt (1982) Characterization of a factor that promotes neurite outgrowth: Evidence linking activity to a heparin sulfate proteoglycan. J. Cell Biol. 94: 574-585.

Latov, N., G. Nilaver, A. Zimmerman, W. G. Johnson, A. Silverman, R. Defendini, and L. Cote (1979) Fibrillary astrocytes proliferate in response to brain injury. Dev. Biol. 72: 381-385.

Lemke, G., and J. Brockes (1984) Identification and purification of glial growth factor. J. Neurol. 4: 75-83.

Letourneau, P. C. (1975) Possible roles for cell-to-substratum adhesion in neuronal morphogenesis. Dev. Biol. 44: 77-91.

Levitt, P., and P. Rakic (1980) Immunoperoxidase localization of glial fibrillary acidic protein in radial glial cells and astrocytes of the developing rhesus monkey brain. J. Comp. Neurol. 1983: 815-840.

Lim, R. (1980) Glia maturation factor. Curr. Top. Dev. Biol. 16:305322.

Ling, E. A. (1981) The origin and nature of microglia. In Advances in Cellular Neurobiology, vol. 2, S. Federoff and L. Hertz, eds., pp. 3382, Academic, New York.

Ling, E. A., C. Kaur, and W. C. Wang (1982) Light and electron microscopic demonstration of nonspecific esterase in ameboid microglial cells in the corpus callosum in postnatal rats: A cytochemical link to monocytes. J. Anat. 135: 385-394.

Matsumoto, Y., and F. Ikuta (1985) Appearance and distribution of fetal brain macrophages in mice. Cell Tissue Res. 239: 271-278.

Miller, R., E. R. Abney, S. David, C. F. French-Constant, R. Lindsay, R. Patel, J. Stone, and M. C. Raff (1986) Is reactive gliosis a property of a distinct subpopulation of astrocytes? J. Neurosci. 6: 22-29.

Murabe, Y., and Y. Sano (1982) Morphological studies on neuroglia VI. Postnatal development of microglial cells. Cell Tissue Res. 225: 464-485.

Pares, M., and R. L. Levine (1982) Long-term degeneration renders central tracts refractory to penetration by regenerating optic fibers. Brain Res. 243: 360-362.

Perry, V. H., D. A. Hume, and S. Gordon (1985) Immunohistochemical localization of macrophages and microglia in the adult and developing mouse brain. Neuroscience 15: 313-326.

Pitas, R. E., T. L. Innerarity, J. N. Weinstein, and R. W. Mahley (1981) Acetoacetylated lipoproteins used to distinguish fibroblasts from macrophages in vitro by fluorescence microscopy. Arteriosclerosis $1: 177-$ 185.

Pruss, R. M., P. F. Bartlett, J. Gavrilovic, R. P. Lisak, and S. Rattray (1981) Mitogens for glial cells: A comparison of the response of cultured astrocytes, oligodendroglia, and Schwann cells. Dev. Brain Res. 2: 19-26.

Raff, M. C., K. L. Fields, S. Hakomori, R. Mirsky, R. M. Pruss, and J. Winter (1979) Cell type specific markers for distinguishing and studying neurons and the major classes of glial cells in culture. Brain Res. 174: 283-308.

Rakic, P. (1972) Mode of cell migration to the superficial layers of the fetal monkey. J. Comp. Neurol. 145: 61-84.

Rio Hortega, P. del (1932) Microglia. In Cytology and Cellular Pathology of the Nervous Systern, vol. 2, W. Penfield, ed., pp. 481-584, Paul P. Hocker, New York.

Schmechel, D. E., and P. Rakic (1979) A Golgi study of radial glial cells in developing monkey telencephalon; morphogenesis and transformation into astrocytes. Anat. Embryol. 156: 115-132.

Schmitt, C., and J. J. Ballet (1983) A microcomputer program for the calculation of interleukin-2 activity. Lymphokine Res. 2: 145-150.

Silver, J., S. E. Lorenz, D. Wahlsten, and J. Coughlin (1982) Axonal guidance during development of the great cerebral commissures: Descriptive and experimental studies in vivo on the role of preformed glial pathways. J. Comp. Neurol. 210: 10-29.

Thiele, D. L., M. Kurosaka, and P. E. Lipsky (1983) Phenotype of the accessory cell necessary for mitogen-stimulated $T$ and $B$ cell responses in human peripheral blood: Delineation by its sensitivity to the lysosomotrophic agent, L-leucine methyl ester. J. Immunol. 131: 22822290.

Valentino, K. L., and E. G. Jones (1981) Morphological and immunocytochemical identification of macrophages in the developing corpus callosum. Anat. Embryol. 163: 157-172. 